\title{
Reverse Side of Multimedia Pedagogics: Clip Thinking
}

\author{
Irina P. Berezovskaya \\ Peter the Great St.Petersburg Polytechnic University, Russia, 195251, St. Petersburg, Polytechnicheskaya, 29 \\ Petersburg State Transport University, Russia 190031 Saint Petersburg, 9 Moskovsky pr. ; Email: ipberezovskaya@mail.ru \\ Olga D. Shipunova
}

Peter the Great St.Petersburg Polytechnic University, Russia, 195251, St. Petersburg, Polytechnicheskaya, 29

\section{Doi:10.5901/mjss.2015.v6n6s1p277}

\section{Abstract}

The article analyzes those cognitive transformations caused by massive introduction of multimedia means into pedagogical process. This theoretical and experimental study of information technologies influence on thinking structure can be justified with the fact that nowadays multimedia have become a megatrend of modern education focusing on "i-generation". The phenomenon of clip thinking is under examination; it is characteristic of reflecting a set of object's various properties without any respect to communications between them, fragmentary nature of information stream, illogicalness, diversity of received information, fast switching between different parts. Identification of typical cognitive transformations of digital information and communicative technologies users and specific psychological characteristics of this new type of thinking, is supposed to be necessary for the purposes of substantial methodological justification of the "clip thinking" concept which would allow this concept untroduction into scientific use and psychological and pedagogical practice.

Keywords: information culture, I - generation, cognitive transformations, clip thinking, multimedia

\section{Introduction}

Various electronic devices and network technologies have now become deeply ingrained into everyday life of modern person. However consequences of such universal information technologies invasion into human life are not fully comprehended. Wide distribution of electronic devices and information and communication technologies moves researchers to pay special attention to those cognitive changes which are possible and currently occur under their influence (Shipunova and Deniskov, 2014, Prensky, 2012).

At the present stage, both experimental study of information technologies influence on cognitive processes, and theoretical judgment of applied research results, and defining further prospects for studying information and communication technologies impact on cognitive processes - all these tasks are quite important. Their relevance is furthermore proved by the fact that negative impact of modern technologies is widely discussed in mass media, between teachers of secondary and higher education, but in scientific community there are none too much research on this phenomenon. The speech of the russian television first channel director K. Ernst at the International television market MIPCOM-2011 (Cannes) illustrates such a situation: "The mentality of people born after the 1980th strongly differs from the mentality of those born earlier. The language they perceive and believe to be adequate, is essentially different. <...> Many of them aren't able to watch one-hour program up to the end. $<\ldots>$ A syndrome of scattered attention is the diagnosis for this generation. It isn't bad, it's just the fact" (Ernst, 2011, Yelyakov, 2011). On the basis of same and similar statements, conclusions are already being drawn about the need to change education system. Then, quite opposite techniques of this change are offered - from teaching technique reconstructing with account of "digital generation" requirements and special "digital wisdom" available to it, up to passing special trainings urged to relieve information and communication technologies impact on thinking. All mentioned statements - so multidirectional, but all so tough in respect to social/какие ценности? Values - are equally dangerous. They promote mass consciousness mytho logization and once again emphasize the need of weighed approach to the problem of information communication technologies impact on thinking.

The traditional requirement of pedagogics - demonstrativeness principle - now leads to mass introduction of multimedia means into education process (projectors, interactive boards used mostly as projector screens, lectures' presentations). Meanwhile, it's not clear whether demonstrativeness increase really facilitate material digestion, and what 
is an actual reason for total aspiration to material visualization - use of modern means to support education process, or the «last choice» for students with unstable attention and nonformed conceptual thinking, who are incapable to allocate the main idea and to structure material? Whether introduction of multimedia into education leads to further degradation of certain cognitive abilities? And if yes, then how critical are these changes, and whether they are compensated with other actively developing abilities?

\section{Materials and Methods}

In order to define the change of thought processes under the influence of information technologies, a group of modern researchers suggest to use concepts "Net-thinking" (Zagidullina, 2012, Pronina, 2001) or "clip thinking". The clip culture metaphor was offered in the 1980th by the American philosopher E. Toffler in his book "The Third Wave" (Toffler, 2004) in the context of information society of new type emerging, which was characterized by "mass media demassification", unified media models dissolution in favor of infinite number of "shooting" incoherent flashes, information fragments - clips.

Marshall Maklewen (Maklyuen, 2005) predicted that electronic communication means development would return human thinking to a level of pre-text epoch, and the linear sequence of signs would stop being the basis of our culture. However it is possible to note that the approach of "post-text" thinking began due to not only electronic communications progress. "Post-industrial epoch thinking" took its first step when newspapers appeared, representing the format of information submission in the form of a large number of short texts non-connected among themselves. In the XIXth century many outstanding persons of traditional European culture understood that the newspaper constituted a terrible anti-cultural force which remade thinking and brought up a special type of the cultural process participant - superficial and scattered one, which was only capable to see the world through a prism of newspaper article and not able to acquire more difficult intellectual production. Parallel to victorious march of telegraph, cable agency and abbreviation, in the sphere of high arts the modernism began to experiment with sense decomposition into incoherent fragments. Futuristic paintings cut the world to cubes and beams, modernist writers broke correctness of linear narration.

In russian science, F.I. Girenok (Girenok, 1995) was one of the first philosophers who used the term "clip thinking", having claimed that the conceptual thinking ceased to play an important role in the modern world and was replaced by the clip thinking. Formation and active development of the last one is inseparably linked with an electronic way of text presentation; this presentation makes a certain contribution into thinking specifics of those persons who spend enough time on the Internet. Implementation of the term generated a number of stereotypes which could be called into question and problematized in our research. Firstly, the clip thinking is considered as an exclusive accessory of youth, children and teenagers. Secondly, it is treated as fully negative phenomenon, as the evil to struggle against. In the USA, they use to treat scattered attention of school students by pharmacological means. In Russia, for this purpose it is recommended to encourage children and teenagers to read more. The famous publicist, the literary critic and the futurologist Sergey Pereslegin (Pereslegin, 2005) considers the clip thinking as the main reason for secondary education decline and suggests passing special trainings which would help to focus attention on one subject. The deacon A. Kurayev says (Regnum, 2004) that "the clip thinking as last prevents person's integrity", because for an individual with internally and externally simple vital world, this world discrepancy increases, and every internal contradiction makes the individual less psychologically steady. E.I. Kogan (Kogan, 2005) notes that under the influence of information, thinking fails to be systematic; the philosopher A.D. Elyakov (Yelyakov, 2011) writes that people immersion to the Internet technologies can lead to thinking degradation.

In 2010, the author of "Clip thinking and destiny of the linear text", the culturologist K.G. Frumkin notes that an epithet "clip thinking" is mostly "awarded" to thinking processes of teenagers and youth, believing that this type of thinking is bad (Frumkin, 2010). Frumkin describes positive and negative characteristics of this thinking type, outlines such negative aspects as mosaicity and separation of environment perception, teenagers and youth unwillingness "to strain" for to work with huge "linear" texts like, for example, "War and peace" by Tolstoy. To positive ones he refers following: clip thinking is organism protective reaction on information overload. The "Clip thinking" phenomenon arise, in Frumkin's opinion, is promoted with following factors: 1) life rhythm acceleration and directly related increase of information streams volume that generates a problem of information selection and reduction, main idea allocation and waste filtration; 2) the need for higher information relevance and speed of its receiving; 3 ) increasing variety of arriving information; 4) increase in number of affairs in which one person is engaged at the same time; 5) growth of dialog city at the different levels of social system. 


\section{Results}

The modern person addresses the Internet for getting information; however structure and system city of information got from the Internet is often so poor that the Internet is even called "all-over-the-world dump", and thinking process of the person addressing to such information storage, is likely to adapt to it. Then it turns out that "digital generation" representatives demonstrate clip thinking more brightly, and it is firstly connected with the fact that they are under supervision of those who use to look for information in absolutely different way (they read linear texts, they look for necessary information in books); secondly, global society informatization of society and incredibly accelerated information exchange during the last decade provides to "digital generation" people the fast simple solution of any difficult task: you don't know - go to Google - receive the answer. "The brevity, the sister of talent" as well as cognitive activity dynamism both are considered as the positive aspects, so they can make provocation to analytic thinking as it makes; L.N. Tolstoy said: "Short thoughts are good for they force the serious reader to think more" (Yeremishin, 2006).

The list can be continued; it is evident that clip thinking possesses not only shortcomings; it just develops one cognitive skill at the expense of others. This phenomenon is inherent, according to Larry Rosen, professor of psychology of the Californian university (Rosen, 2007), to the "I" generation which has grown up during the era of computer and communication technologies boom. Larry Rosen makes the distinction between generation born in the 80th ("network" one) and born in the late 90th ("i-generation"). Representatives of "network generation" rather actively use phone, not less than two hours a day, and also communicate via e-mail. "I-generation" to much more extent use text messages for communication, instead of phone, pays much less attention to the TV and try to use different networks for communication. Those of $16-18$ years are capable to carry out seven tasks at the same time: print SMS messages, communicate on Skype, check e-mail, do all these thinks along with watching TV program. Twenty-year-old young people, according to Rosen's data, can cope at the same time only with six cases, and those over 30 - with five and a half. Multitask is considered to be specific for "clip thinking", however there is a question: what is the refer point to define thinking as multitask and at the same time "clip"?

\section{Discussion}

There is no unambiguous definition of clip thinking, but on the base of written sources it is possible to make the conclusion: "clip thinking" is a process of reflection of a whole set of various object properties, without communications between them, characterized by fragmentarity of information stream, illogicalness, full diversity of arriving information, high speed of switching between parts, information fragments, lack of complete picture of environment perception (Semenovskikh, 2013). Works of modern researchers about "clip" thinking are presented by articles; butsystem work isn't present so far. Whether it is possible to speak about "clip" thinking not in "clip" manner?

It also can be noted that philosophical scientific community pays more or less attention to the phenomenon of "clip thinking"; but Russian psychological scientific literature only declares the fact of IT technologies impact on cognitive processes development without any quantitative and qualitative analysis of these changes. Philosophers, while characterizing "clip thinking", mostly mention the features specific of not thinking itself, but perception, memory, attention. Meanwhile transformations of informative processes during the epoch of information technologies boom can be defined in terms of classical psychology: as the degree of information perception fragmentarily, conceptual thinking, critical thinking formation, development of attention switch in the expense of concentration, etc.

In fact, in order to exactly define the phenomenon of "clip thinking" it is necessary to fix, describe and analyze those changes in the cognitive sphere of modern person which deal with logic of understanding as the main component of successful intellectual action both in the training situation and in routine life. The understanding of situation acts as the general principle to which one can refer mentioned psychological parameters of cognitive sphere transformation in the description of clip thinking phenomenon. Each person not only processes input visual information, but mentally builds models and scenarios of cultural and socio-political interpretation of current events, using with different degree of consciousness these or those norms and templates. In cognitive approach, understanding of situation is modeled via "frames" forming a basis of contextual expectations concerning upcoming events, setting boundaries of possible interpretations. Thus the pragmatically factor, defined on the one hand by presentation, on the other - by importance and relevance of semantic image which activates contextual semantic links, is extremely important. Then process of understanding appears as template recognition. 


\section{Conclusion}

The analysis of informative processes of digital information and communicative technologies users is quite necessary, which would be aimed at detecting specific psychological characteristics of possible new type of thinking, as well as substantial methodological justification of "clip thinking" concept and perspective of its introduction into scientific turn.

The outlined goals are to be achieved through solving following tasks:

1. Identification of interrelations between features of media consumption and characteristics of perception, memory, attention and thinking of individuals.

2. Comparative analysis of clip thinking, conceptual thinking and pre-conceptual thinking

3. Identification of interrelations between features of individuals' media activity and the level of critical thinking development.

4. Revealing factors, which drop down information processing efficiency, and factors, which promote the most successful process of cultural experience transfer.

5. Analysis of the revealed factors implementation in educational process.

6. Revealing the identifying descriptions of "clip" thinking.

If interaction from mass media, firstly digital, represents the key factor defining changes in informative processes development in the XXIh century, the quantity and quality of changes is to depend on intensity and substantial filling of this experience. Determination of features of respondents' information behavior which would reveal features of experience of interaction from mass media, application of psychological techniques to examine the level of informative processes development would allow establishing existence or lack of correlation between media behavior of individuals and features of the cognitive sphere. Such research should involve respondents of different age groups; one age group (student's youth), but mastering different professions (conditionally "technical" - "natural-science" - "humanitarian"); with various digital experience contents (preference of information search, Internet communication, Internet creativity, online games, etc.) and quantitative parameters (duration of Internet experience and its intensity). Usage of mathematical statistics methods included in an IBM SPSS Statistics 21 package would allow establishing distinctions between the surveyed groups and interrelations between the studied.

\section{References}

Ernst, K. (2011). When they say that the Internet will kill television, is foolish. Kommersant, 192 (4)

Frumkin, K.G. (2010) Clip thinking and fate of linear text. Ineternum, 1. http://nounivers.narod.ru/pub/kf_clip.htm

Girenok, F.I. (1995). Metaphysics PATA (tongue-tie a tired person). Moscow: Labirint.

Karr N. (2012) The Shallows: What the Internet Is Doing to Our Brains. SPb.: Best Biznes Buks.

Kogan Ye.I. (2005). Reading needs to be protected. Russian intellectualism in America: Articles. Portraits. Reviews, S (140-146).

Maklyuen, M. (2005). The Gutenberg Galaxy: The Making of Typographic Man. M.: Akademicheskiy proyekt.

Pereslegin S.B. (2005) The tutorial game on the world chessboard. M.: AST, SPb.: Terra Fantastica.

Pronina, Ye. Ye. (2001). Live text: four stylistic trait Net-thinking. Vestnik MGU. Ser. 10, 6 (74-80)

Prensky M. (2012). From digital natives to digital wisdom: Hopeful essays for 21st century learning. Thousand Oaks, CA: Corwin Press.

Rosen, L. (2007). Me, MySpace, and I: Parenting the Net Generation. N.Y.

Shipunova O.D., Deniskov A.V. (2014). Subculture of the information society: interaction design in industrial environments. Issues cultural studies, 6 (87-91).

Semenovskikh T.V. Clip thinking" - the phenomenon of modernity. The best communication: Epistemic resource from the Academy of media industry and the Department of the theory and practice of social connectedness RSUH. http://jarki.ru/wpress/2013/02/18/ 3208.

The clip hostages of thinking. Interview with Andrey Kurayev. Regnum, 2004. http://www.rg.ru/2004/05/13/Kuraev.htm

Toffler E. (2004). The third wave. Moscow: AST.

Yelyakov A.D. (2011). Good and evil: burning paradox of the Internet. Philosophy and society, 2 (71-72).

Yeremishin O. (2006). Aphorisms. Golden Fund of wisdom. M.: Prosveshcheniye.

Zagidullina M.V. (2012). Information society in the context of the net-thinking. Bulletin Of The CSU, Ser. Philology, 63 (48-50) 